\title{
NUMERICAL INVESTIGATION OF LOCAL HEAT TRANSFER DISTRIBUTION ON SURFACES WITH A NON-UNIFORM TEMPERATURE UNDER AN ARRAY OF IMPINGING JETS WITH VARIOUS NOZZLE SHAPES
}

\author{
KRZYSZTOF MARZEC \\ Rzeszow University of Technology, Rzeszów, Poland and MTU Aero Engines, Rzeszów, Poland \\ e-mail:k_marzec@prz.edu.pl \\ Anna KuCABA-Piętal \\ Rzeszow University of Technology, Rzeszów, Poland
}

\begin{abstract}
Numerical calculations of heat transfer characteristics of an impingement cooling system with a non-uniform temperature on a cooled surface using ANSYS CFX have been performed. The influence of a surface heat flux $q_{w}(x)$ and a nozzle shape on the Nusselt number distribution on the cooled surface has been studied. The setup consisted of a cylindrical plenum with an inline array of ten impingement jets. Cylindrical, convergent divergent shapes of nozzles and linear temperature distribution on the cooled surface have been considered for various heat fluxes $q_{w}(x)$. Results indicate that geometry of the cylindrical nozzles resulted in the highest Nusselt numbers along the cooled surface. The line of the averaged Nusselt number has a trend to increase in the direction of the flow for the cooling system with increasing values of the surface heat flux $q(x)$. This tendency can be observed for all presented shapes of jets. On the other hand, for decreasing functions of the heat flux $q_{w}(x)$, the Nusselt number distribution is more uniform. It can be observed for all types of nozzles. Very similar values of the Nusselt number occur especially for the non-uniform heat flux $5000-2500 \mathrm{~W} / \mathrm{m}^{2}$. For constant values of the heat flux $q(x)=5000 \mathrm{~W} / \mathrm{m}^{2}$, the line of the average Nusselt number has a trend to increase slightly in the direction of the flow. Numerical analysis of different mesh density results in good convergence of the GCI index, what excludes mesh size dependency. The presented study is an extension of the paper (Marzec and Kucaba-Piętal, 2016) and aims at answering the question how the Nusselt number distribution on the cooled surface is affected by various geometries of nozzles for a non-uniform surface heat flux $q_{w}(x)$.
\end{abstract}

Keywords: impinging jet, heat transfer, Nusselt number, nozzle shape

\section{Introduction}

An impingement cooling system is an array of jets with a high velocity fluid which is made to strike a target surface. It is an effective method to generate a high cooling rate on a surface of a hot object. Impingement jets are widely used in many engineering applications for cooling, drying or heating. Many of cooling systems are installed, in particular, in electronic devices, aeronautical and heavy industry equipment and many others. Technological processes are supported by impinging jets. Cooling nozzles are used in various geometrical configurations implementing either a single injector or several parallel jets. Wide application of cooling systems is due to the fact that modern devices and machines operate at very high temperatures. Therefore, usage of impingement cooling systems is mandatory to provide a high rate of heat and mass transfer. In gas turbine engines, impinging jets are applied for cooling turbine blades and casings (Active Clearance Control) (Ahmed et al., 2010; Andreini et al., 2013; Ruiz et al., 2006), which operate at very high temperatures. Besides the high heat transfer, cooling systems reduce fuel consumption of engines. A number of experimental and numerical studies have dealt with the investigation of 
the heat transfer between an air jet and a flat surface (Al-Hadhrami et al., 2007, 2010; Mubarak et al., 2011). Many of them are focused on the high Nusselt number delivery (Goordo et al., 2007). Heat transfer rates in the case of impinging jets are affected by various parameters like the Reynolds number, jet to plate spacing, radial distance from a stagnation point, target plate inclination, nozzle geometry, roughness of the target plate and turbulence intensity at the nozzle exit. The majority of studies are experimental ones (Goordo et al., 2007; Nirmalkumar et al., 2011). However, many simulations of impingement cooling systems are numerical (Ee-Mahghany et al., 2012; Żukowski, 2013). It is remarkable that only few are addressed to the problem of cooling a surface with an inhomogeneous distribution of temperature (Tarabsheh et al., 2013; $\mathrm{Xu}$ et al., 2014). Such a situation occurs in many technical applications such as photovoltaic cells (Royne et al., 2005). Tarabsheh et al. (2013) presented research on the performance of photovoltaic (PV) modules with respect to the non-uniform temperature and proposed various pipe layouts. The operating temperatures of the PV cells are not equal since the temperature of the flowing fluid is different at the inlet and outlet of the cooling pipes. Different geometries of cooling pipes were introduced in order to maximize the PV module efficiency. The results show that implementation of various cooling pipes improved the efficiency of the PV cells. Xu et al. (2014) presented a multi-channel cooling experiment which was developed for studying heat removal inside an electronic device. The results showed that the designed multi-channel heat sink structure could control the temperature distribution of the device with multiple heat sources by altering the coolant flow rate and different design of the cooling multi-channel structure. Marzec and Kucaba-Piętal (2014) presented the influence of different geometries of nozzles of an impingement cooling array directed to the flat surface on a flow mechanism and heat transfer at constant temperature on the cooled surface. The obtained results indicate that the usage of various types of nozzles results in different values of the heat transfer coefficient and the Nusselt number along the cooled surface. In turn, Marzec and Kucaba-Piętal (2016) focused on heat transfer characteristics of a cooling system with a non-uniform temperature on the cooled surface. Three decreasing linear functions of a heat flux $q_{w}(x)$ were reviewed. The most uniform Nusselt number distribution was observed along the cooled surface for the heat flux $q_{w}(x)=5000-2500 \mathrm{~W} / \mathrm{m}^{2}$. Additionally, Marzec and Kucaba-Piętal (2016) investigated heat transfer characteristics for a constant surface heat flux $q_{w}(x)=5000 \mathrm{~W} / \mathrm{m}^{2}$. It is worth to note that research work by Marzec and Kucaba-Pietal (2016) was addressed only to the usage of cylindrical nozzles.

This paper presents numerical analysis of the effect of nozzle shape on the heat transfer performance. The cooling surface posses both decreasing and increasing linear temperature distributions. Cylindrical, convergent and divergent geometry of the nozzles are taken into consideration like in the work by Marzec and Kucaba-Piętal (2014). Calculations are performed using Computational Fluid Dynamics (CFD) code Ansys CFX. The $k-\omega$ shear stress transport (SST) turbulence model is used in the calculations.

The results show that the line of the averaged Nusselt number has a trend to increase in the direction of the flow for the cooling system with increasing values of the surface heat flux $q_{w}(x)$. This tendency occurs for all presented shapes of the jets. For the decreasing functions of the heat flux $q_{w}(x)$, the Nusselt number distribution is more homogenous. It can be observed for all geometries of the nozzles. Very similar values of the Nusselt number occur especially for the non-uniform heat flux 5000-2500 W/ $\mathrm{m}^{2}$.

\section{Problem formulation}

The geometry of the numerical setup is presented in Fig. 1. Geometry, fluid, thermal and flow data used for the calculations are the same as in the work by Marzec and Kucaba-Piętal (2016) and are equal to the values presented in Table 1. 


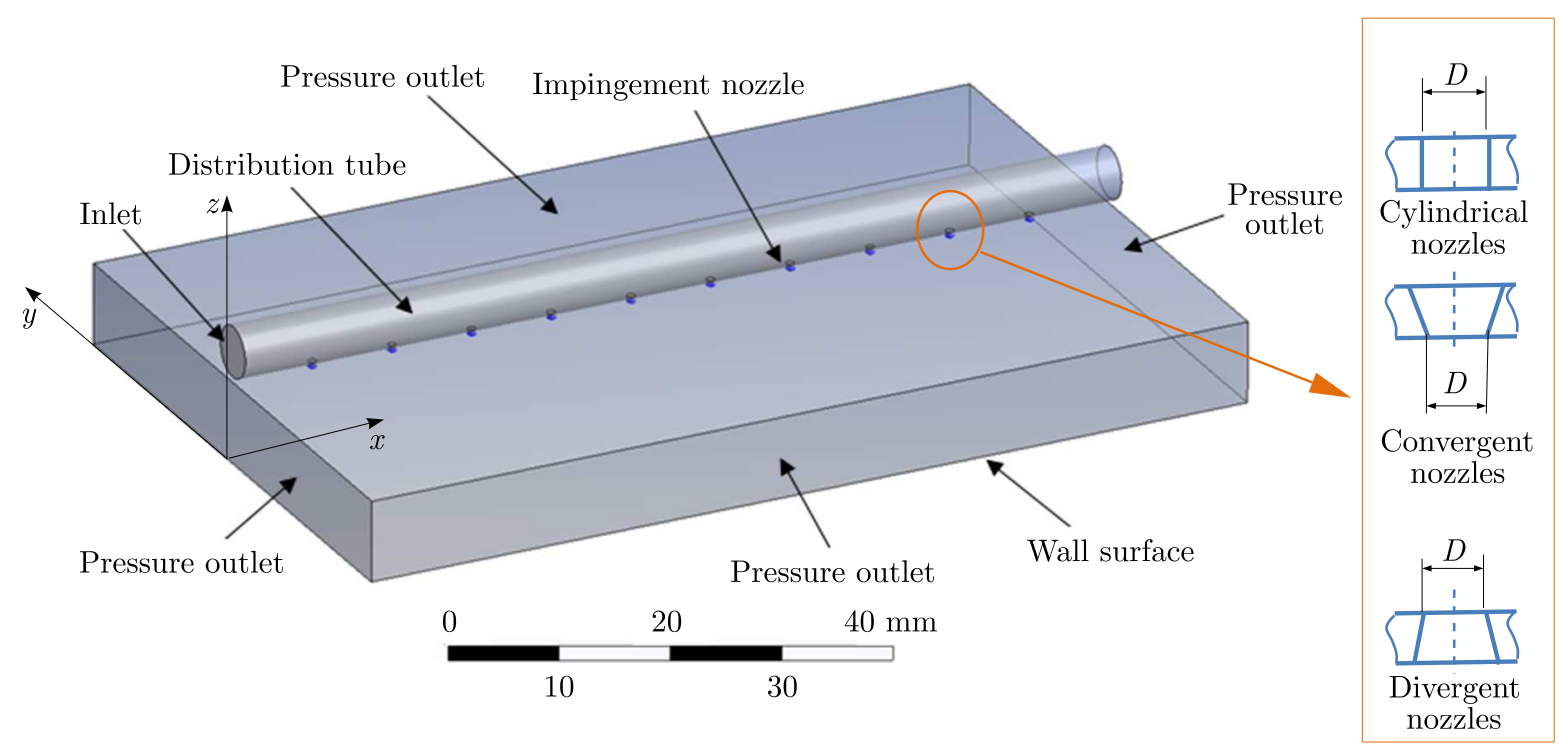

Fig. 1. Investigated computational 3D domain

Table 1. Geometry, fluid data, thermal and flow parameters used for calculations

\begin{tabular}{|c|c|c|l|}
\hline Symbol & Value & Unit & \multicolumn{1}{|c|}{ Description } \\
\hline \hline$D$ & 0.8 & $\mathrm{~mm}$ & nozzle diameter \\
\hline$\alpha$ & 30 & ${ }^{\circ}$ & taper angle \\
\hline$z / D$ & 8 & - & nozzles exit-plate distance \\
\hline$S / D$ & 8 & - & nozzle pitch-diameter ratio \\
\hline$D_{T}$ & 5 & $\mathrm{~mm}$ & distribution tube inlet diameter \\
\hline$L$ & 88 & $\mathrm{~mm}$ & length of target plate \\
\hline$W$ & 56 & $\mathrm{~mm}$ & width of target plate \\
\hline$T_{j e t}$ & 20 & ${ }^{\circ}$ & fluid temperature in jet area \\
\hline$u$ & 14 & $\mathrm{~m} / \mathrm{s}$ & inlet air velocity \\
\hline $\operatorname{Re}$ & 4800 & - & Reynolds number in jet area \\
\hline$\rho$ & 1.17 & $\mathrm{~kg} / \mathrm{m}^{3}$ & air density \\
\hline$k$ & 0.025 & $\mathrm{~W} /(\mathrm{mK})$ & thermal conductivity \\
\hline$\mu$ & $1.8 \cdot 10^{-5}$ & Pas & dynamic viscosity \\
\hline
\end{tabular}

The presented cooling system consists of an array of ten impingement nozzles directed normally to the flat surface. Three different geometries of the nozzles are taken into consideration: cylindrical, convergent and divergent. Geometry of all the jets is based on the study by Royne and Dey (2006). Consequently, for the convergent and divergent nozzles, a taper angle $\alpha=30^{\circ}$ is introduced.

Both the left and the right hand side of the system are open to allow the fluid to flow. The fluid is free to expand after impinging the target surface.

Impingement cooling systems (especially gas turbines) have to operate with temperature differences on the cooled casing up to $250^{\circ} \mathrm{C}$. Considering this and based on formula from Vinze et al. (2016) a heat flux range $q_{w}(x)=0-5000 \mathrm{~W} / \mathrm{m}^{2}$ has been established. To define the influence of the non-uniform heat flux on the results of calculations, four different functions $q_{w}(x)$ have been defined including the pointed range $q_{w}(x)=0-5000 \mathrm{~W} / \mathrm{m}^{2}$. Both increasing and decreasing values have been taken into account. They are presented in Tables 2 and 3. 


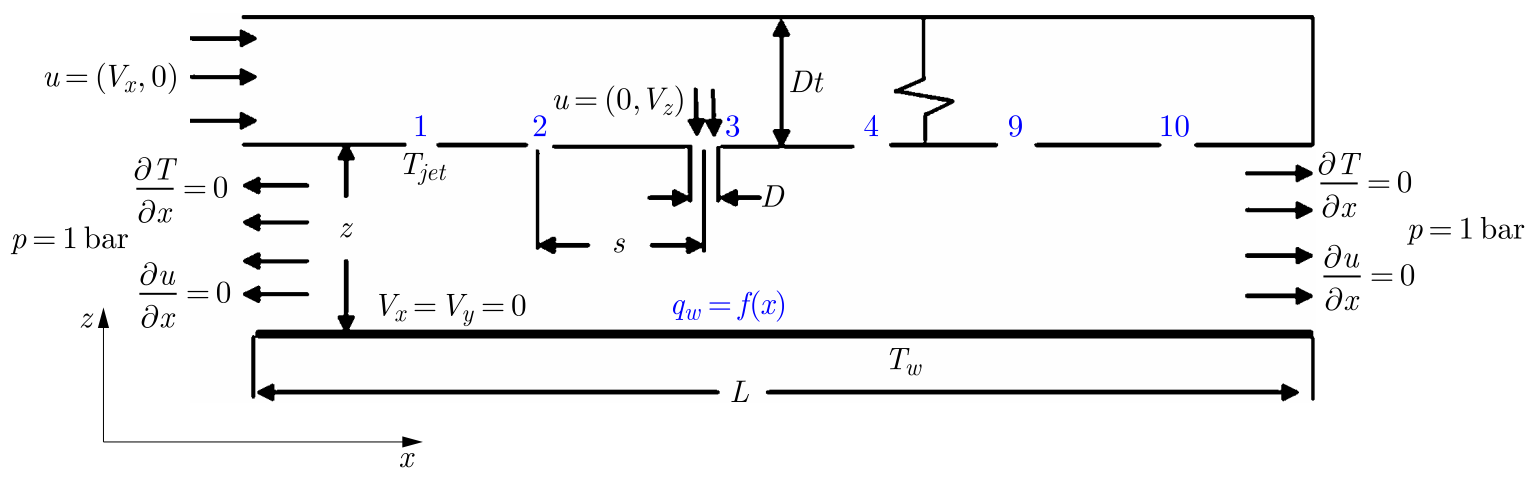

Fig. 2. 2D diagram of the considered problem (Marzec and Kucaba-Piętal, 2016)

Table 2. Cooled surface heat flux $q_{w}(x)$ representation by increasing linear functions

\begin{tabular}{|c|c|c|c|c|}
\hline No. & $\begin{array}{c}\text { Heat flux function } \\
q_{w}(x)\end{array}$ & $\begin{array}{c}q_{w}(0) \\
{\left[\mathrm{W} / \mathrm{m}^{2}\right]}\end{array}$ & $\begin{array}{c}q_{w}(88) \\
{\left[\mathrm{W} / \mathrm{m}^{2}\right]}\end{array}$ & $\begin{array}{c}\text { Graph of function } \\
q_{w}(x)\end{array}$ \\
\hline \hline 1 & $56.82 x$ & 0 & 5000 & $q_{w}(x)$ \\
\hline 2 & $45.45 x+1000$ & 1000 & 5000 & $q_{w}(x)$ \\
\hline 3 & $28.41 x+2500$ & 2500 & 5000 & $q_{x}$ \\
\hline
\end{tabular}

Table 3. Cooled surface heat flux $q_{w}(x)$ representation by decreasing linear functions

\begin{tabular}{|c|c|c|c|c|}
\hline No. & $\begin{array}{c}\text { Heat flux function } \\
q_{w}(x)\end{array}$ & $\begin{array}{c}q_{w}(0) \\
{\left[\mathrm{W} / \mathrm{m}^{2}\right]}\end{array}$ & $\begin{array}{c}q_{w}(88) \\
{\left[\mathrm{W} / \mathrm{m}^{2}\right]}\end{array}$ & $\begin{array}{c}\text { Graph of function } \\
q_{w}(x)\end{array}$ \\
\hline \hline 1 & $-56.82 x+5000$ & 5000 & 0 & \\
\hline 2 & $-45.45 x+5000$ & 5000 & 1000 & \\
\hline 3 & $-28.41 x+5000$ & 5000 & 2500 & $q_{w}$ \\
\hline
\end{tabular}

\section{Governing correlations}

The heat transfer rate measurements along the impingement surface are presented in terms of the Nusselt number as

$$
\mathrm{Nu}=\frac{h D}{k}
$$

where $h$ is the heat transfer coefficient, $D$ is nozzle diameter, and $k$ is conductivity of the fluid. The heat transfer coefficient is defined as

$$
h=\frac{q_{w}}{T_{w}-T_{j e t}} \quad h=-k \frac{1}{T_{j e t}-T_{w}} \frac{\partial T}{\partial z}
$$


where $q_{w}$ is the wall heat flux, $T_{w}$ is the wall adiabatic temperature, $T_{j e t}$ is the jet temperature, $\partial T / \partial z$ gives the temperature gradient component normal to the wall.

In this study, the line averaged Nusselt Number is defined as below

$$
\overline{\mathrm{Nu}}=\frac{1}{L} \int_{L} \mathrm{Nu}(x) d x
$$

where $L$ is the line of the plate parallel to the distribution tube axis.

\section{Numerical methods}

\subsection{Numerical approach}

The 3D analysis of the heat transfer characteristics is carried out using Computational Fluid Dynamics (CFD) software Ansys CFX that solves equations of continuity, momentum end energy using the Reynolds-Averaged Navier-Stokes approach (RANS). In the RANS treatment, velocity vectors and other functions (in this case pressure) are split into average values and fluctuations, what can be written as follows (Błoński, 2009)

$$
\begin{aligned}
& u_{i}(x, y, z, t)=\bar{u}_{i}(x, y, z)+u_{i}^{\prime}(x, y, z, t) \\
& p(x, y, z, t)=\bar{p}(x, y, z)+p^{\prime}(x, y, z, t)
\end{aligned}
$$

where $i=1,2,3, u_{i}$ are velocity vector components, $p$ - pressure.

Based on this approach, the Navier-Stokes equations of continuity and momentum can be written as follows

$$
\begin{aligned}
& \frac{\partial \bar{u}_{j}}{\partial x_{j}}=0 \\
& \frac{\partial}{\partial x_{j}}\left(\rho \overline{u_{i} u_{j}}\right)=-\frac{\partial \bar{p}}{\partial x_{i}}+\frac{\partial}{\partial x_{j}}\left[\left(\frac{\partial \bar{u}_{i}}{\partial x_{j}}+\frac{\partial \bar{u}_{j}}{\partial x_{i}}\right)\right]+\frac{\partial}{\partial x_{j}}\left(-\rho \overline{u_{i}^{\prime} u_{j}^{\prime}}\right) \quad i, j=1,2,3
\end{aligned}
$$

The correlations between the velocity fluctuations appearing in the momentum equations act as stresses and are called Reynolds stresses. They are defined as below

$$
\left(-\rho \overline{u_{i}^{\prime} u_{j}^{\prime}}\right)=\mu_{t}\left(\frac{\partial \bar{u}_{i}}{\partial x_{j}}+\frac{\partial \bar{u}_{j}}{\partial x_{i}}\right)-\frac{2}{3} \rho \delta_{i j} k
$$

where $\mu_{t}$ is turbulent viscosity, $k$ - turbulence kinetic energy

$$
k=\frac{1}{2}\left(\overline{u_{i}^{\prime} u_{j}^{\prime}}\right)
$$

Finally, the Navier-Stokes equations for the stationary and viscous flow of the fluid can be written as follows

$$
\begin{aligned}
& \frac{\partial}{\partial x_{j}}\left(\rho \overline{u_{i} u_{j}}\right)=-\frac{\partial \bar{p}}{\partial x_{i}}+\frac{\partial}{\partial x_{j}}\left[\left(\mu+\mu_{t}\right)\left(\frac{\partial \bar{u}_{i}}{\partial x_{j}}+\frac{\partial \bar{u}_{j}}{\partial x_{i}}\right)\right]-\frac{2}{3} \frac{\partial}{\partial x_{j}}(\rho k) \\
& \frac{\partial \bar{u}_{j}}{\partial x_{j}}=0
\end{aligned}
$$

In the present investigation, the $k$ - $\omega$ shear stress transport (SST) turbulence model is used. It combines the $k-\omega$ model near the wall and the $k-\varepsilon$ model further from the wall. This approach utilizes strengths of each model. SST model is recommended as the best method for the impinging jet heat transfer predictions (Zuckerman and Lior, 2006). 
The investigation is limited to the steady state assumption, and dynamic features of the impinging jets are ignored. However, the steady state assumption is able to provide average flow and temperature fields. To validate the numerical technique and the solution procedure, the comparison of numerical results of an impingement cooling system of the surface with a uniform temperature distribution with experimental have been performed and showed satisfying agreement (Marzec and Kucaba-Piętal, 2013).

\subsection{Initial and boundary conditions}

The velocity of the flow $u=\left(V_{x}, V_{z}\right)$ at the inlet of the supply tube $V_{x}=14 \mathrm{~m} / \mathrm{s}$ is constant for the whole analysis and is prescribed to obtain the Reynolds number $R e=4800$ in the area of the cylindrical nozzle. Thereby, the Reynolds number is based on the mean velocity at the nozzle and jet diameter $D$. The outlet boundaries of the calculated domain are represented by opening pressure boundary conditions which permit the fluid to both enter or leave the domain. The ambient pressure is constant at $p=1$ bar. The fluid entering the plenum has total temperature of $T_{j e t}=20^{\circ} \mathrm{C}$ which corresponds to temperature of the ambient air. The wall and the jet impinged onto have various heat fluxes $q_{w}(x)$. The walls of the cylindrical plenum are unheated and are modeled as an adiabatic no-slip wall. To simplify the analysis, the steady-state incompressible viscous fluid flow is considered. Moreover, it is assumed that the fluid physical properties are constant and the effect of the gravity and radiation is neglected. The flow field is three-dimensional. The roughness of the tube which contains the flowing fluid is $30 \mu \mathrm{m}$.

\subsection{Numerical grids and numerical accuracy}

The geometry of the nozzles supporting the tube and the cooled surface, which were described previously, are taken into account in the grid definition which consists of $1.79 \mathrm{mln}$ elements and 323119 nodes of unstructured tetrahedral grids generated by the Ansys CFX mesher. The influence of the numerical grid density on the results of the heat transfer coefficient and the Nusselt number in the stagnation region is taken into consideration. Four analyses with different cell sizes in the area of the interface (between the air flow and the surface) were performed. To investigate the sensitivity of the numerical results analysis, the Grid Convergence Index GCI (Eq. (4.1)) is calculated (Xu et al., 2014). This is the most frequently used method for estimation of numerical uncertainty, endorsed by ASME Journal of Fluid Engineering (ASME, 2008). The safety factor $F_{s}=3$, has been set for two grids comparison. Temperature is the chosen parameter. It is measured in the cooled surface for each grid. The order of convergence is $p=2, r^{p}$ is the density factor. In the third analysis, GCI $=1.3 \%$ has been obtained. Therefore, it might be concluded that numerical results for the fine grid are grid independent

$$
\mathrm{GCI}=F_{s} \frac{1}{r^{p}-1}\left|\frac{T_{h 2}-T_{h 1}}{T_{h 1}}\right| \cdot 100 \%
$$

\section{Results and discussion}

This Section presents the analysis of heat transfer characteristics of an array of ten impingement jets directed normally to the flat surface with various ways of the surface heat flux $q_{w}(x)$ distribution. Beside cylindrical nozzles, the usage of convergent and divergent jets are taken into consideration in terms of heat transfer characteristics with an inhomogeneous distribution of the surface heat flux $q_{w}(x)$. Flow field characteristics of the impingement cooling system with ten cylindrical nozzles is presented in the work Marzec and Kucaba-Piętal (2016). The optimal system configuration for a given surface heat flux $q_{w}(x)$ will be determined by the constant mass flow rate, the uniform Nusselt number distribution on the cooled surface and a high rate of 
heat transfer. The uniform Nusselt number $\overline{\mathrm{Nu}}$ distribution plays a significant role as it might reduce thermal stresses on the cooled surface. In Fig. 3, the Nusselt number $\overline{\mathrm{Nu}}$ corresponding to the usage of ten cylindrical, convergent and divergent nozzles with the constant heat flux $q_{w}(x)=5000 \mathrm{~W} / \mathrm{m}^{2}$ is presented. For the cylindrical nozzles, the usage of a constant heat flux $q_{w}=5000 \mathrm{~W} / \mathrm{m}^{2}$ results in the highest averaged Nusselt number $\overline{\mathrm{Nu}}=4.59$. The usage of convergent and divergent nozzles results in a very similar value of the averaged Nusselt number $\overline{\mathrm{Nu}}=3.59$ and $\overline{\mathrm{Nu}}=3.52$, respectively. The lowest values of the heat transfer rate are achieved for divergent nozzles in the area of the first jet. This is caused because of the flow deflection angle. In addition, it can be seen that for all nozzle geometries, the line of the averaged Nusselt number increases slightly in the $x$ direction (along the flow of the distribution tube). The maximum difference between cylindrical, convergent and divergent nozzles, in the Nusselt Number $\mathrm{Nu}_{o}$ is respectively $31.5 \%, 36 \%$ and $42 \%$.

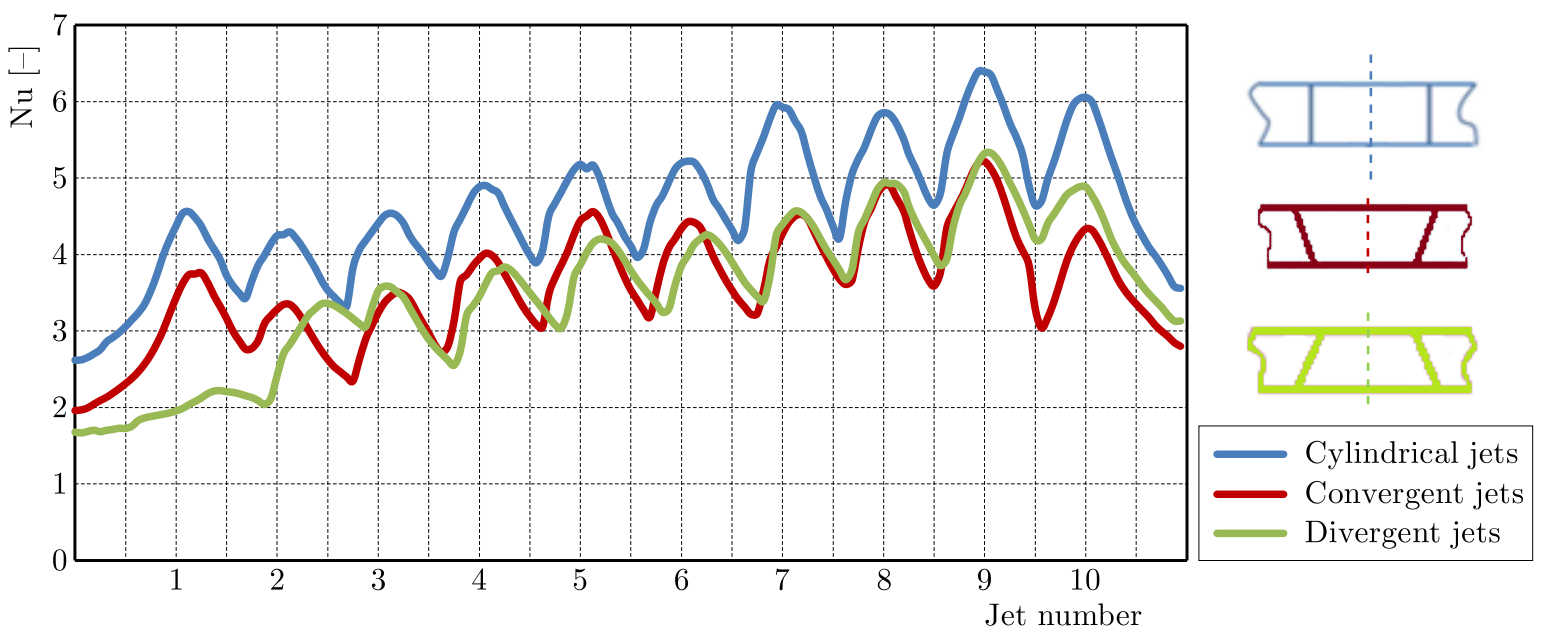

Fig. 3. Area of the averaged Nusselt number $\overline{\mathrm{Nu}}$ for cylindrical, convergent, divergent jets and a constant surface heat flux $q_{w}=5000 \mathrm{~W} / \mathrm{m}^{2}$

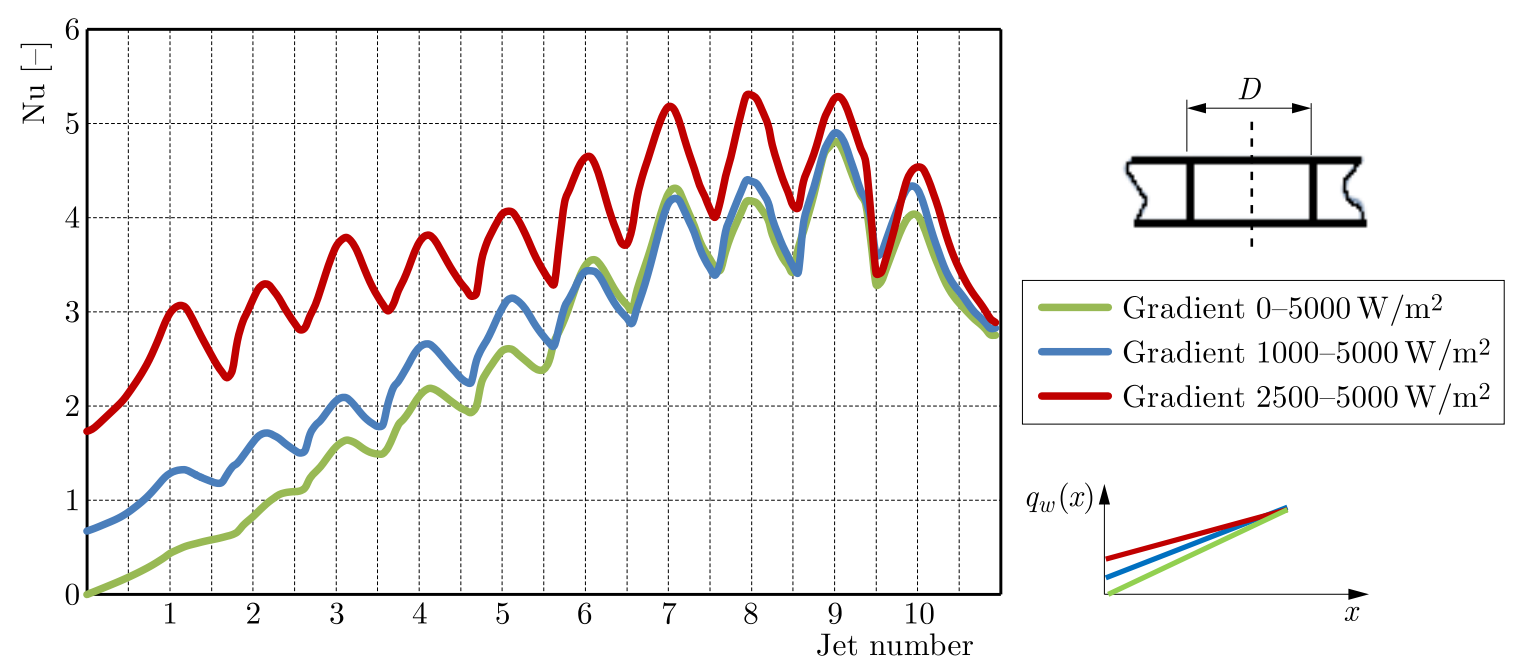

Fig. 4. Area of the averaged Nusselt number $\overline{\mathrm{Nu}}$ for the increasing heat flux $q_{w}(x)$, cylindrical nozzles

In Fig. 4, the Nusselt number corresponding to the application of ten cylindrical nozzles with the increasing heat flux $q_{w}(x)$ is presented. The wall, the jet impinged onto, is heated with a heat flux represented by three different linear functions (Table 2). The first one represents the heat flux $q_{w}=0 \mathrm{~W} / \mathrm{m}^{2}$ at the beginning of the cooled surface and $q_{w}=5000 \mathrm{~W} / \mathrm{m}^{2}$ at the end 
of the cooled surface. The second one represents the heat flux $q_{w}=1000-5000 \mathrm{~W} / \mathrm{m}^{2}$. The third one represents the heat flux $q_{w}=2500-5000 \mathrm{~W} / \mathrm{m}^{2}$. It can be seen that the line of the averaged Nusselt number increases in the direction of the flow in the distribution tube for all three heat flux functions. The heat flux distribution $q_{w}=2500-5000 \mathrm{~W} / \mathrm{m}^{2}$ represents the most uniform values of the Nusselt number $\mathrm{Nu}_{o}$ in the stagnation region across all of the jets. The average difference of the Nusselt number $\mathrm{Nu}_{o}$ is $19.8 \%$.

In Fig. 5, the Nusselt number corresponding to making use of ten convergent nozzles with a variable heat flux $q_{w}(x)$ increasing in the direction of the flow is presented. The wall, the jet impinged onto, is heated with the heat flux represented by three different linear functions (Table 2). The first one represents the heat flux $q_{w}=0 \mathrm{~W} / \mathrm{m}^{2}$ at the beginning of the cooled surface and $q_{w}=5000 \mathrm{~W} / \mathrm{m}^{2}$ at the end of the cooled surface. The second one represents the heat flux $q_{w}=1000-5000 \mathrm{~W} / \mathrm{m}^{2}$. The third one represents the heat flux $q_{w}=2500-5000 \mathrm{~W} / \mathrm{m}^{2}$. It can be seen that the line of the averaged Nusselt number increases in the direction of the flow in the distribution tube for all three heat flux functions. The heat flux distribution $q_{w}=2500$ $5000 \mathrm{~W} / \mathrm{m}^{2}$ represents the most uniform values of the Nusselt number $\mathrm{Nu}_{o}$ in the stagnation region across all of the jets. The average difference of the Nusselt number $\mathrm{Nu}_{o}$ is $27.1 \%$.

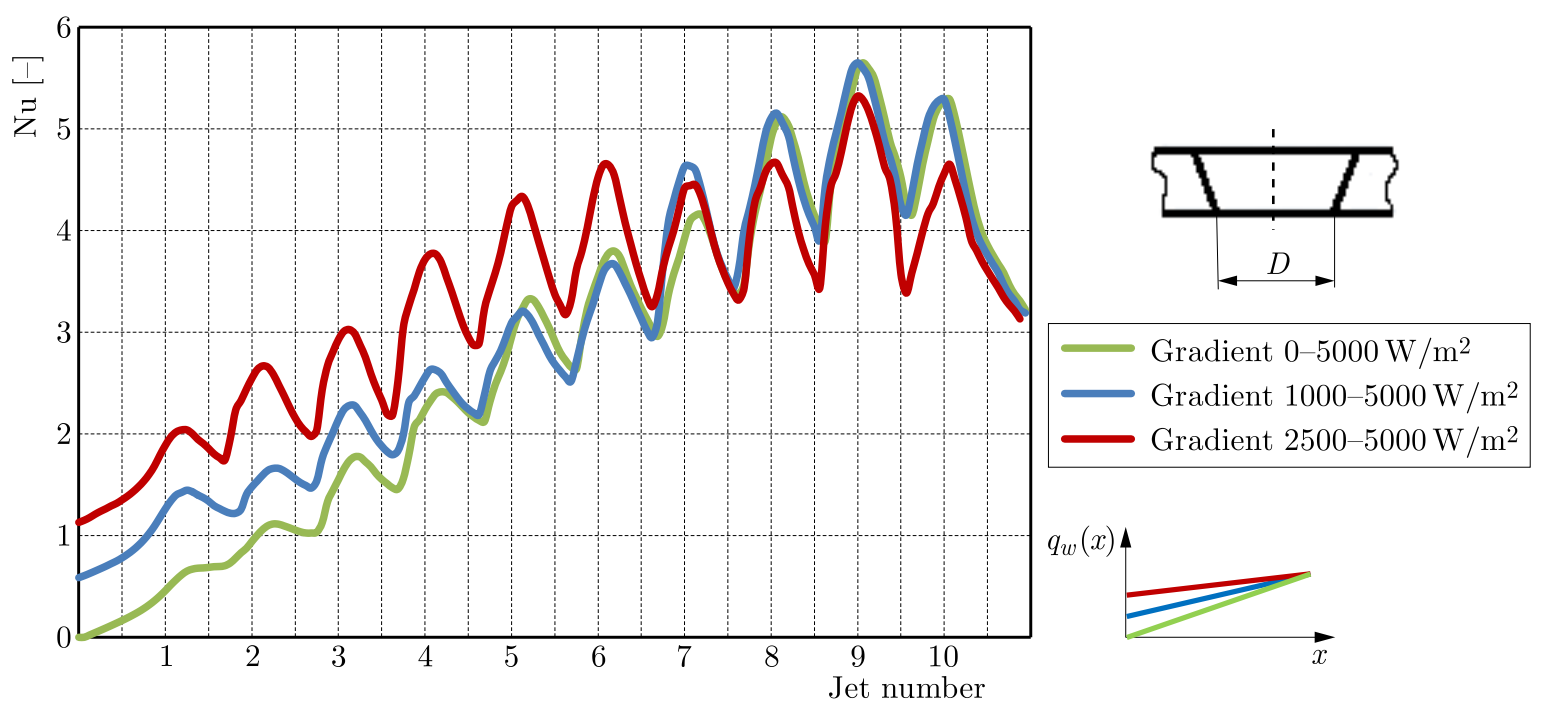

Fig. 5. Area of the averaged Nusselt number $\overline{\mathrm{Nu}}$ for the increasing heat flux $q_{w}(x)$, convergent nozzles

Figure 6 presents the Nusselt number corresponding to the usage of ten convergent nozzles with a variable heat flux $q_{w}(x)$ decreasing in the direction of the flow. The wall, the jet impinged onto, is heated with the heat flux represented by three different linear functions (Table 3). The first one represents the heat flux $q_{w}=5000 \mathrm{~W} / \mathrm{m}^{2}$ at the beginning of the cooled surface and $q_{w}=0 \mathrm{~W} / \mathrm{m}^{2}$ at the end of the cooled surface. The second one represents the heat flux $q_{w}=5000$ $-1000 \mathrm{~W} / \mathrm{m}^{2}$. The third one represents the heat flux $q_{w}=5000-2500 \mathrm{~W} / \mathrm{m}^{2}$. It can be seen that the line of the averaged Nusselt number decreases in the direction of the flow in the distribution tube for the first and the second heat flux function. The heat flux $q_{w}=5000-2500 \mathrm{~W} / \mathrm{m}^{2}$ represents similar values of the Nusselt number $\mathrm{Nu}_{o}$ in the stagnation region for all of the jets. The average difference of the Nusselt number $\mathrm{Nu}_{o}$ is $13 \%$.

In Fig. 7, the Nusselt number corresponding to incorporation of ten divergent nozzles with a variable heat flux $q_{w}(x)$ increasing in the direction of the flow is presented. The wall, the jet impinged onto, is heated with the heat flux represented by three different linear functions (Table 2). The first one represents the heat flux $q_{w}=0 \mathrm{~W} / \mathrm{m}^{2}$ at the beginning of the cooled surface and $q_{w}=5000 \mathrm{~W} / \mathrm{m}^{2}$ at the end of the cooled surface. The second one represents the heat flux $q_{w}=1000-5000 \mathrm{~W} / \mathrm{m}^{2}$. The third one represents the heat flux $q_{w}=2500-5000 \mathrm{~W} / \mathrm{m}^{2}$. It can 

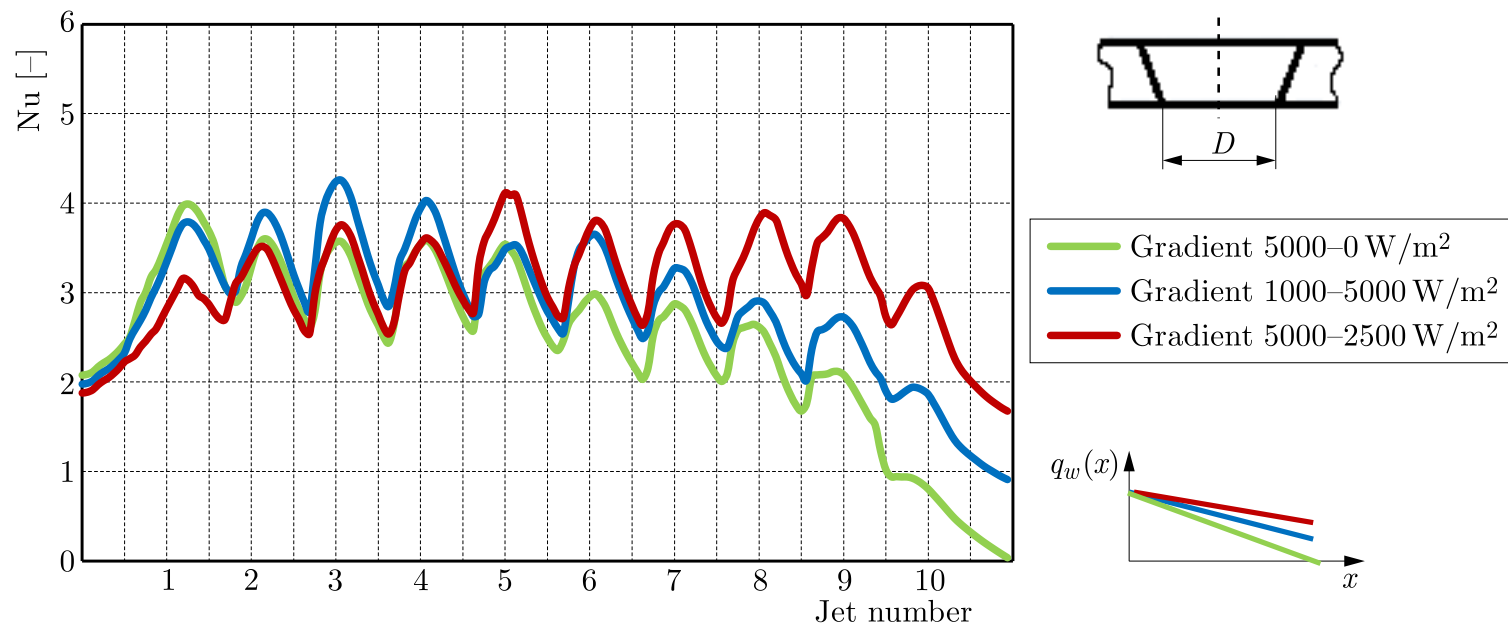

$q_{w}(x)$

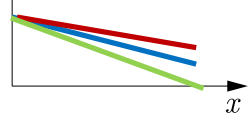

Fig. 6. Area of the averaged Nusselt number $\overline{\mathrm{Nu}}$ for the decreasing heat flux $q_{w}(x)$, convergent nozzles
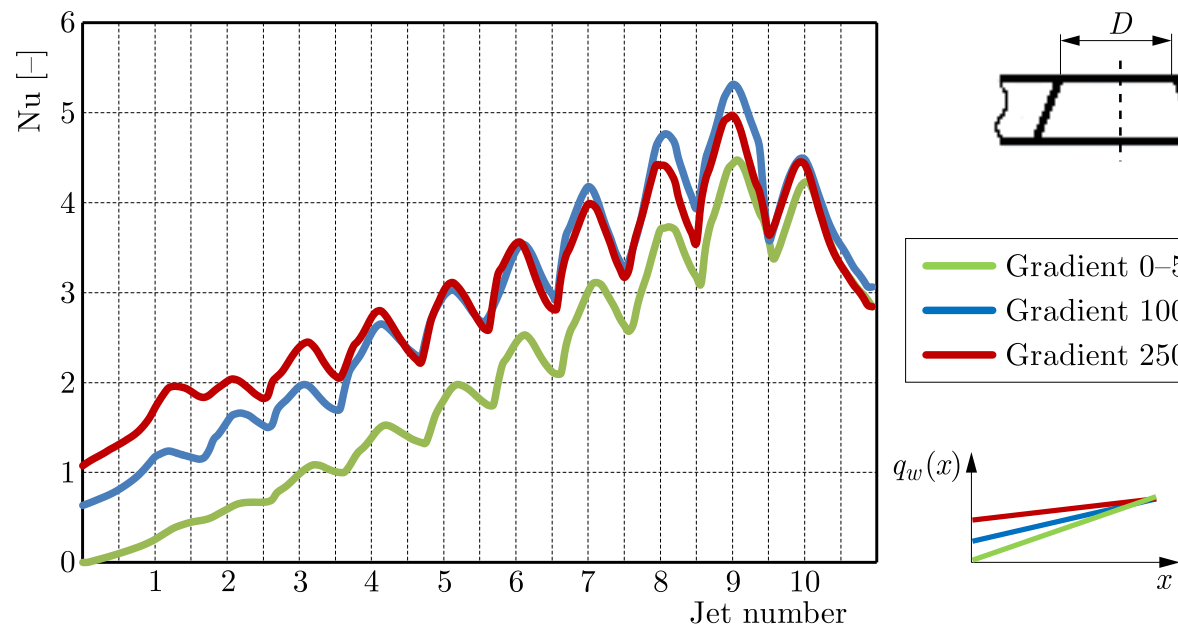

Fig. 7. Area of the averaged Nusselt number $\overline{\mathrm{Nu}}$ for the increasing heat flux $q_{w}(x)$, divergent nozzles
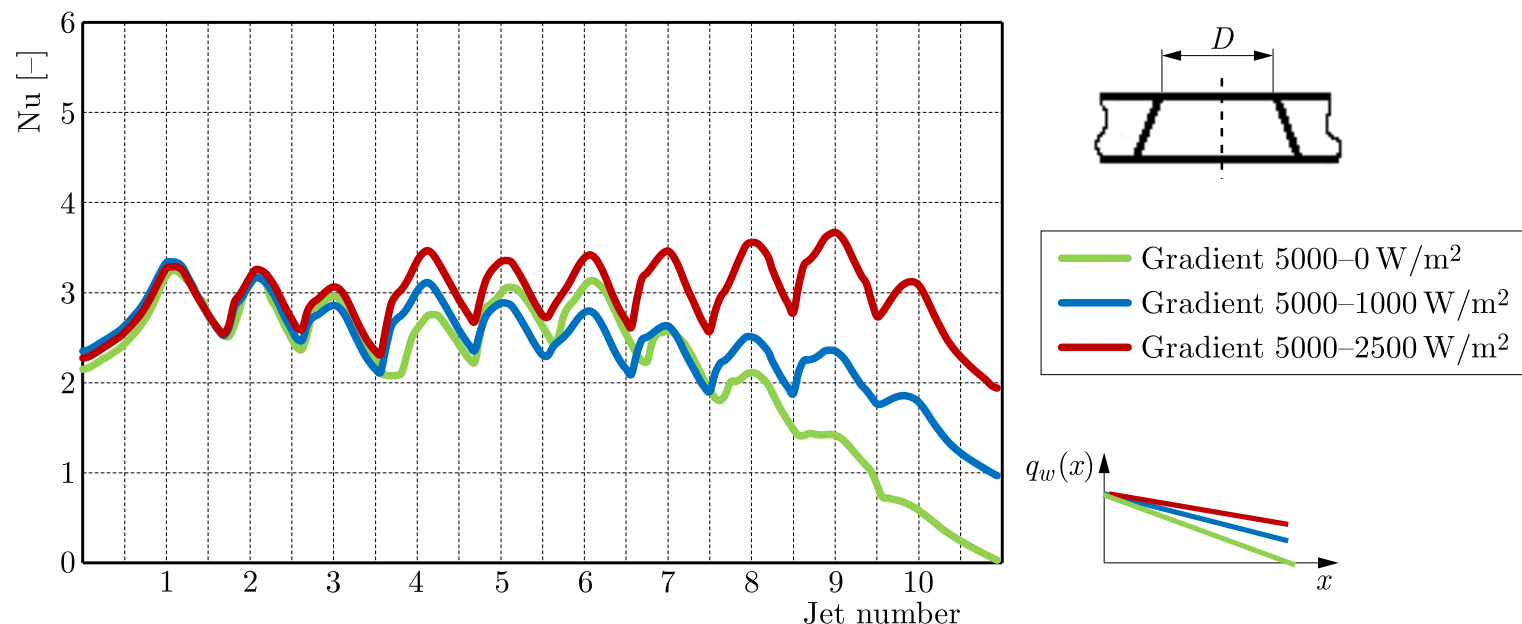

Fig. 8. Area of the averaged Nusselt number $\overline{\mathrm{Nu}}$ for the decreasing heat flux $q_{w}(x)$, divergent nozzles 
be seen that the line of the averaged Nusselt number has a trend to increases in the direction of the flow in the distribution tube for all three heat flux functions. For $q_{w}=2500-5000 \mathrm{~W} / \mathrm{m}^{2}$, the average difference of the Nusselt number $\mathrm{Nu}_{o}$ is $34.3 \%$.

Figure 8 presents the Nusselt number corresponding to application of ten divergent nozzles with a variable heat flux $q_{w}(x)$ decreasing in the direction of the flow. The wall, the jet impinged onto, is heated with the heat flux represented by three different linear functions (Table 3). The first one represents the heat flux $q_{w}=5000 \mathrm{~W} / \mathrm{m}^{2}$ at the beginning of the cooled surface and $q_{w}=0 \mathrm{~W} / \mathrm{m}^{2}$ at the end of the cooled surface. The second one represents the heat flux $q_{w}=5000-$ $-1000 \mathrm{~W} / \mathrm{m}^{2}$. The third one represents the heat flux $q_{w}=5000-2500 \mathrm{~W} / \mathrm{m}^{2}$. It can be seen that the line of the averaged Nusselt number decreases in the direction of the flow in the distribution tube for the first and the second heat flux functions. The heat flux $q_{w}=5000-2500 \mathrm{~W} / \mathrm{m}^{2}$ represents similar values of the Nusselt number $\mathrm{Nu}_{o}$ in the stagnation region for all of the jets. The average difference of the Nusselt number $\mathrm{Nu}_{o}$ is $9.1 \%$.

\section{Conclusions}

The aim of the work is numerical analysis of the Nusselt number distribution of an array of ten impingement jets when the cooling surface posses both decreasing and increasing linear temperature distributions (see Tables 2 and 3). Cylindrical, convergent and divergent geometry of the nozzles are taken into consideration. The making use of an array of cooling jets resulted in a uniform distribution of the mass flow among the nozzles. The results indicate that cylindrical geometry of the nozzles results in the highest Nusselt numbers along the cooled surface. The results are convergent with a situation when temperature of the cooled surface is constant (Marzec and Kucaba-Piętal, 2014).

Taking into consideration the heat flux functions $q_{w}(x)$, the line of the averaged Nusselt number has a trend to increase in the direction of the flow for the cooling system with increasing values of the surface heat flux. This tendency can be observed for all presented shapes of the jets. On the other hand, for the decreasing functions of the heat flux $q_{w}(x)$, the Nusselt number distribution is more uniform. It can be observed for all types of the nozzles. For the non-uniform heat flux $5000-2500 \mathrm{~W} / \mathrm{m}^{2}$, very similar values of the Nusselt number $\mathrm{Nu}_{o}$ along the cooled surface can be noticed. For constant values of the heat flux $q_{w}(x)=5000 \mathrm{~W} / \mathrm{m}^{2}$, the line of the averaged Nusselt number has a trend to increase slightly in the direction of the flow. The presented results prove that the shape of the nozzles as well as an the inlet of the system have an impact on the Nusselt number distribution on the cooled plate. It can be interesting for designers of cooling systems who have to handle with the considered problem.

Acknowledgements

The calculations have been performed at ICM UW, Grant G64-0.

\section{References}

1. Ahmed F.B., Weigand B.. Meier K., 2010, Heat transfer and pressure drop characteristic for a turbine casing impingement cooling system, Procedings of 14 th International Heat Transfer Conference, Washington, 5

2. Al-Hadhrami L.M., 2010, Study of a heat transfer distribution in a channel with inclined target surface cooled by a single array of staggered impinging jets, Heat Transfer Engineering, 31, 234-242 
3. Al-Hadhrami L.M., Shanhid S.M., Mubarak A., 2007, Heat transfer in a channel with inclined target surface cooled by a single array of staggered impinging jets, Proceedings of the ASME Turbo Expo, Montreal, Canada, 35-42

4. Andreini A., da Soghe R., Facchini B., Maiuolo F., Tarchi L., Coutandin D., 2013, Experimental and numerical analysis of multiple impingement jet arrays for an active clearance control system, Journal of Turbomachinery, $\mathbf{1 3 5}$

5. ASME, 2008, Procedure for estimation and reporting of uncertainty due to discretization in CFD applications, Journal of Fluids Engineering, 130

6. BŁoński S., 2009, Laminar-turbulent flow analysis in micro-channels, PhD Thesis, Polish Academy of Science, Institute of Fundamental Technological Research, http://www.ippt.pan.pl/_download/doktoraty/blonski_doktorat.pdf

7. Ee-Mahghany W.M., Hanafy A.A., Khaled M.A., Mohamed A.T., 2012, Numerical simulation for confined rectangular slot jets impingement on isothermal horizontal plate, European Journal of Science Research, 76, 553-566

8. Goordo M., Jongmyung P., Ligrani P., Fox M., Hee-Koo M., 2007, Effects of Mach number and Reynolds number on jet array impingement, International Journal of Heat and Mass Transfer, 50, 367-380

9. Marzec K., Kucaba-Piectal A., 2013, Applications of computer science in impingement cooling system design, Pre-Proceedings of 9th International Conference on Applied Mathematics, Baia Mare, Romania

10. Marzec K., Kucaba-Piętal A., 2014, Heat transfer characteristic of an impingement cooling system with different nozzle geometry, Journal of Physics: Conference Series, $\mathbf{5 3 0}$

11. Marzec K., Kucaba-Piętal A., 2016, Numerical investigation of heat transfer characteristics of an impingement cooling system with non-uniform temperature on a cooled surface, Journal of Physics, Conference Series, $\mathbf{7 4 5}$

12. Mubarak A., Shanhid S.M., Al-Hadhrami M., 2011, Impact of jet Reynolds number and feed channel geometry on heat transfer in a channel with inclined target surface cooled by single array of centered impinging jets with outflow in both directions, Proceedings of International Conference of Mechanical Engineering, London, UK, 6-8

13. Nirmalkumar M., Katti V., Prabhu S.V., 2011, Local heat transfer distribution on a smooth flat plate impinged by a slot jet, International Journal of Heat and Mass Transfer, 54, 727-738

14. Royne A., Dey CH., 2006, Effect of nozzle geometry on pressure drop and heat transfer in submerged jet arrays, International Journal of Heat and Mass Transfer, 49, 800-804

15. Royne A., Dey Ch., Mills D., 2005, Cooling of photovoltaic cells under concentrated illumination: a critical review, Solar Energy Materials and Solar Cells, 86, 451-483

16. Ruiz R., Alberts B., Sak W., Seitzer K., Steinetz B., 2006, Benefits of improved HP turbine active clearance control, NASA/CP2007-214995/Vol 1 Air System Workshop, Cleveland, OH

17. SAn J., ShiaO W., 2006, Effect of jet plate size and plate spacing on the stagnation Nusselt number for a confined circular air jet impinging on a flat surface, International Journal of Heat and Mass Transfer, 49, 3477-3486

18. Tarabsheh A., Voutetakis S., Papadopoulos A., Seferlis P., Etier I., Saraereh O., 2013, Investigation of temperature effects in efficiency improvement of non-uniformly cooled photovoltaic cells, Chemical Engineering Transactions, 35

19. Vinze R., Chandel S., Limaye M.D., Prabhu S.V., 2016, Influence of jet temperature and nozzle shape on the heat transfer distribution between a smooth plate and impinging air jets, International Journal of Thermal Sciences, 99, 136-151 
20. Xu Sh., Wang W., Guo Z., Hu X., Guoa W., 2014, Multi-channel cooling system for multiple heat source, Thermal Science Online Issue, 00, 123

21. ZuCKerman N., Lior N., 2006, Jet impingement heat transfer: physics, correlations and numerical modeling, Advanced in Heat Transfer, 39

22. Żukowski M., 2013, Heat transfer performance of a confined single slot jet if air impinging on a flat surface, International Journal of Heat and Mass Transfer, 57, 484-490

Manuscript received March 19, 2017; accepted for print June 5, 2017 